\title{
Arbeidsmarktprognoses 2026
}

Citation for published version (APA):

Bakens, J., Bijlsma, I., Dijksman, S., Fouarge, D., \& Goedhart, R. (2021). Arbeidsmarktprognoses 2026.

ROA. ROA Fact Sheets No. 002 https://doi.org/10.26481/umarof.2021002

Document status and date:

Published: 08/07/2021

DOI:

10.26481/umarof.2021002

Document Version:

Publisher's PDF, also known as Version of record

\section{Please check the document version of this publication:}

- A submitted manuscript is the version of the article upon submission and before peer-review. There can be important differences between the submitted version and the official published version of record.

People interested in the research are advised to contact the author for the final version of the publication, or visit the DOI to the publisher's website.

- The final author version and the galley proof are versions of the publication after peer review.

- The final published version features the final layout of the paper including the volume, issue and page numbers.

Link to publication

\footnotetext{
General rights rights.

- You may freely distribute the URL identifying the publication in the public portal. please follow below link for the End User Agreement:

www.umlib.nl/taverne-license

Take down policy

If you believe that this document breaches copyright please contact us at:

repository@maastrichtuniversity.nl

providing details and we will investigate your claim.
}

Copyright and moral rights for the publications made accessible in the public portal are retained by the authors and/or other copyright owners and it is a condition of accessing publications that users recognise and abide by the legal requirements associated with these

- Users may download and print one copy of any publication from the public portal for the purpose of private study or research.

- You may not further distribute the material or use it for any profit-making activity or commercial gain

If the publication is distributed under the terms of Article $25 \mathrm{fa}$ of the Dutch Copyright Act, indicated by the "Taverne" license above, 


\section{VERWACHTE VRAAG NAAR ARBEID TOT 2026 VALT LAGER UIT}

Hoewel het herstel van de werkgelegenheid na de Covid-19-pandemie dit en volgend jaar spoedig verloopt, zijn de vooruitzichten voor de komende 6 jaar minder gunstig dan vóó de pandemie geraamd werd.

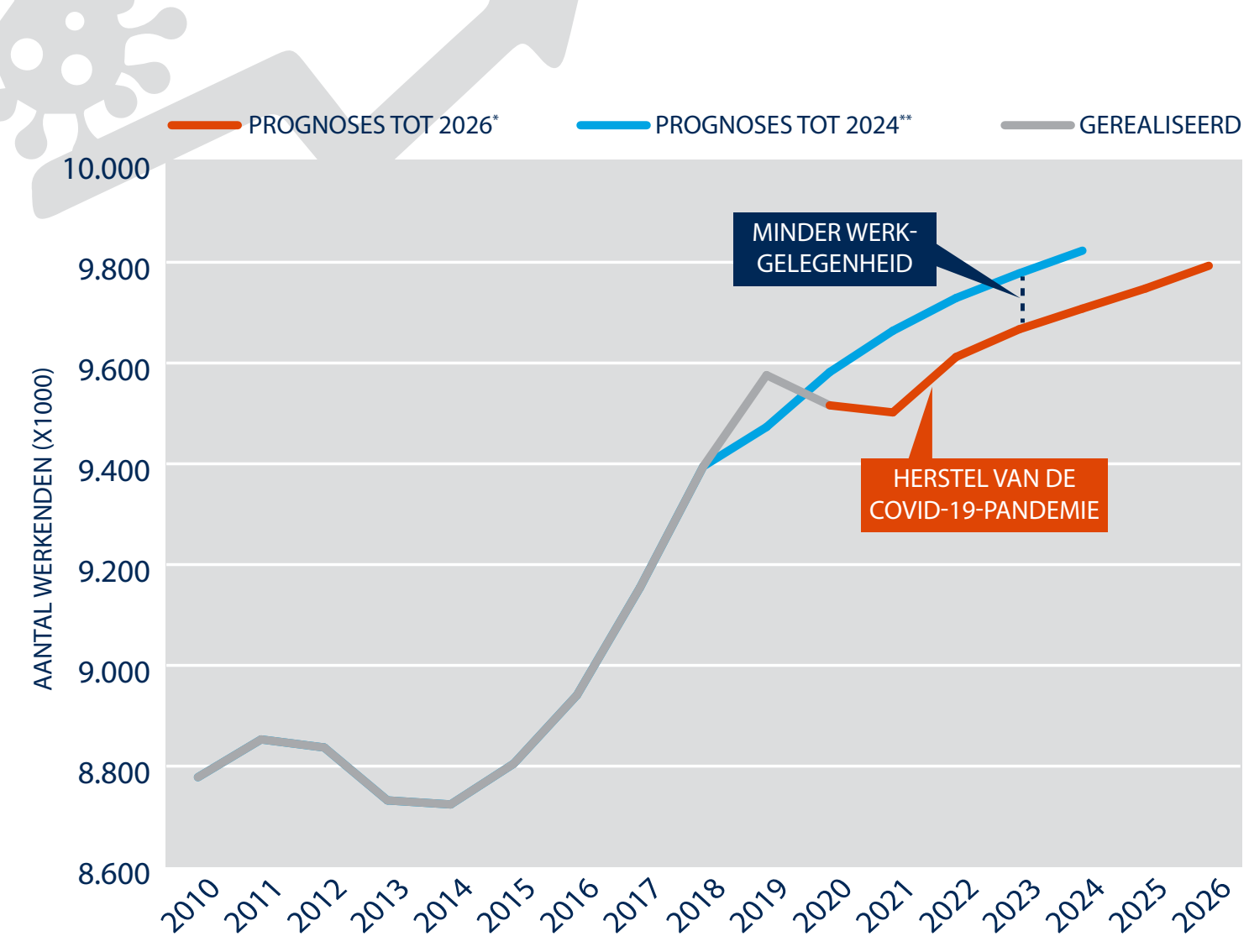

ARBEIDSMARKTPERSPECTIEVEN VOOR OPLEIDINGEN

\begin{tabular}{|c|c|c|c|}
\hline $\mathrm{MBO}_{3}$ & $\mathrm{MBO}_{4}$ & BACHELOR & MASTER \\
\hline $\begin{array}{l}\text { LANDBOUW } \\
\text { EN NATUUR }\end{array}$ & $\begin{array}{l}\text { LANDBOUW } \\
\text { EN NATUUR }\end{array}$ & $\begin{array}{l}\text { LANDBOUW } \\
\text { EN NATUUR }\end{array}$ & $\begin{array}{l}\text { LANDBOUW } \\
\text { EN NATUUR }\end{array}$ \\
\hline $\begin{array}{l}\text { TECHNIEK } \\
\text { EN ICT }\end{array}$ & TECHNIEK & $\begin{array}{l}\text { TECHNIEK } \\
\text { EN ICT }\end{array}$ & $\begin{array}{l}\text { TECHNIEK } \\
\text { EN ICT }\end{array}$ \\
\hline $\begin{array}{l}\text { ECONOMIE EN } \\
\text { MAATSCHAPPIJ }\end{array}$ & $\begin{array}{l}\text { ECONOMIE EN } \\
\text { MAATSCHAPPIJ }\end{array}$ & $\begin{array}{l}\text { ECONOMIE EN } \\
\text { MAATSCHAPPIJ }\end{array}$ & $\begin{array}{l}\text { ECONOMIE EN } \\
\text { MAATSCHAPPIJ }\end{array}$ \\
\hline $\begin{array}{l}\text { ZORG EN } \\
\text { DIENSTVERLENING }\end{array}$ & \begin{tabular}{|l|} 
ZORG EN \\
DIENSTVERLENING
\end{tabular} & $\begin{array}{l}\text { ZORG EN } \\
\text { ONDERWIJS }\end{array}$ & $\begin{array}{l}\text { ZORG EN } \\
\text { ONDERWIJS }\end{array}$ \\
\hline GOED & REDELIJK & MATIG & SLECHT \\
\hline
\end{tabular}

* ROA (2021). De arbeidsmarkt naar opleiding en beroep tot 2026. ROA-R-2021/5

** ROA (2019). De arbeidsmarkt naar opleiding en beroep tot 2024. ROA-R-2019/7

\section{$2 m \ln$}

BAANOPENINGEN

TOT 2026

Over de komende zes jaar worden er

meer dan 2 miljoen baanopeningen

verwacht. Het feit dat mensen

vervangen moeten worden die (tijdelijk)

de arbeidsmarkt verlaten door o.a.

pensionering en arbeidsongeschiktheid

zorgt voor bijna $90 \%$ van de baan-

openingen. De overige vraag wordt

veroorzaakt door economische groei.

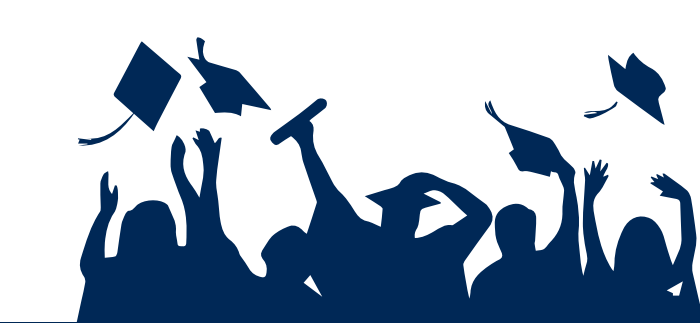

$1,6 \mathrm{mln}$

INSTROMERS

TOT 2026

SLECHT
GROTE KNELPUNTEN VOOR WERKGEVERS IN ONDERWIJS-, TECHNIEK-, ICT- EN ZORGBEROEPEN
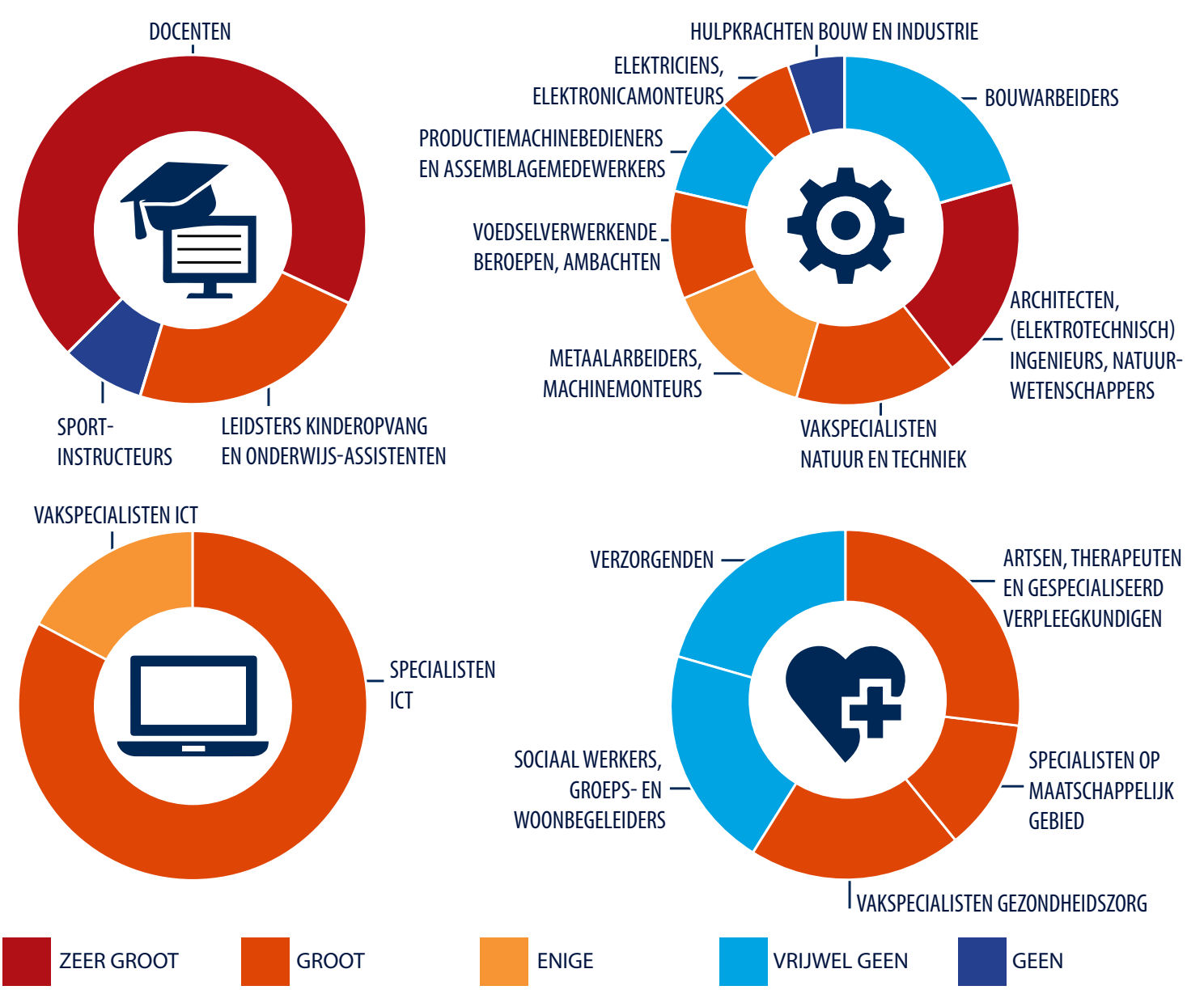

ONZEKERHEID

De prognoses zijn omgeven door meer onzekerheid omdat de korte en langere termijneffecten van de Covid-19-pandemie op de vraag- en aanbodkant van de arbeidsmarkt nog onduidelijk zijn. Dit heeft betrekking op de effecten op de economische groei maar ook op lange termijn trends zoals automatisering, skills upgrading en flexibilisering.

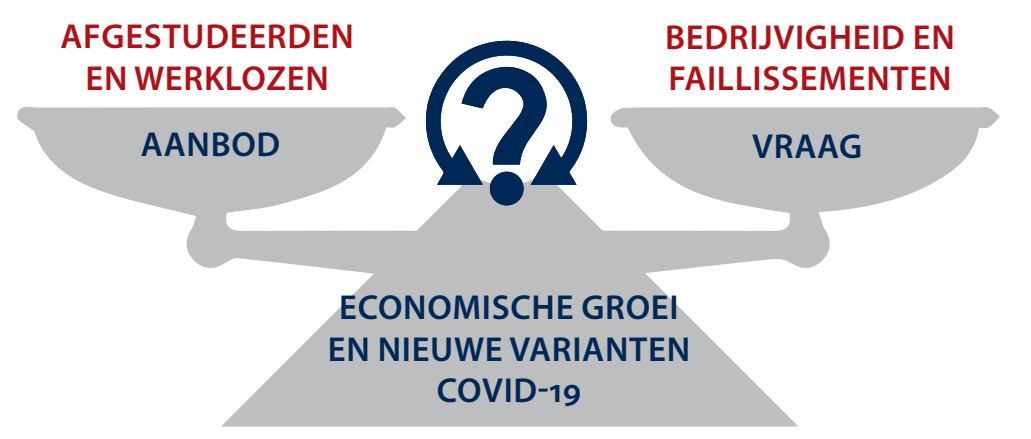

www.roa.nl 